\title{
Medical Image of the Week: Massive Spontaneous Intra-Abdominal Bleeding
}

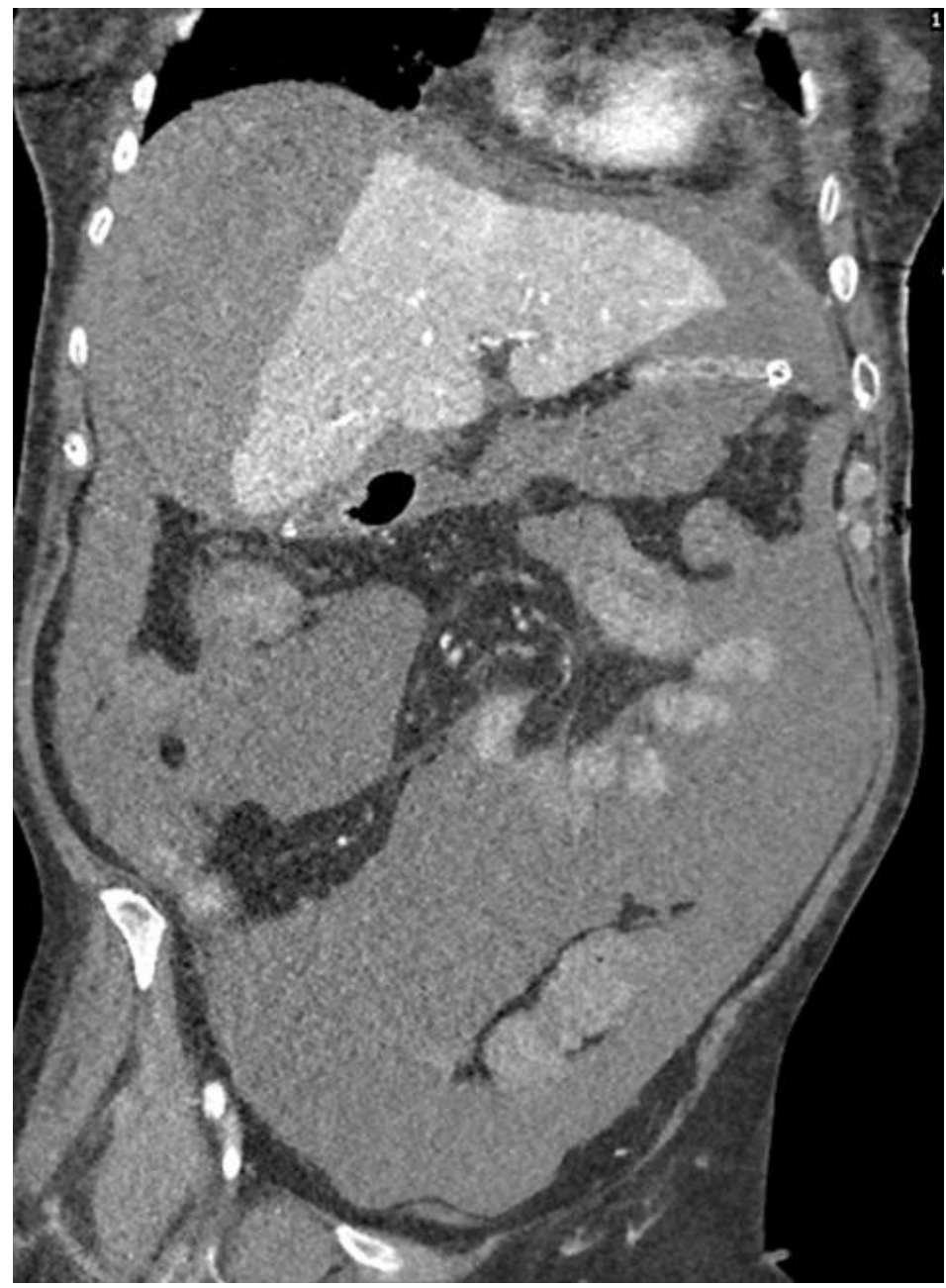

Figure 1. CT scan of the abdomen and pelvis showing diffuse intra-abdominal bleeding.

A 67 year-old female with rheumatoid arthritis, on anti-TNF and corticosteroids, was admitted to the ICU with severe shock, likely hemorrhagic. She was on coumadin for atrial fibrillation. She was found to have severe coagulopathy and diffuse spontaneous abdominal bleeding (Figure 1). She also developed left popliteal artery thrombosis, with compartment syndrome requiring surgical intervention. Disseminated intravascular coagulation was her final diagnosis.

Mohammed Alzoubaidi MD, Carmen Luraschi-Monjagatta MD, Sridhar Reddy MD, Robert McAtee MD.

Departments of Pulmonary and Critical Care, Internal Medicine and Emergency Medicine

South Campus

Tucson, Arizona 